\title{
LAS ARMAS COMO CONCEPTO FISCAL Y DE DIFERENCIACION SOCIAL EN LA BAJA EDAD MEDIA (Aplicación al caso de Ciudad Rodrigo)
}

\author{
POR \\ ANGEL BERNAL ESTEVEZ
}

\section{El CARÁCTER DEFINIDOR DE LAS ARMAS}

LA organización fiscal medieval es un aspecto que da carácter a la población. Podría decirse que la simple estratificación social en estamentos se consagra en la práctica con un planteamiento fiscal selectivo que obedece a esa división jurídica. El concepto de exento o de pechero, que viene a ser casi lo mismo que decir privilegiado o no privilegiado, es tan explícito, claro y significativo para una gran parte de la población — salvando ciertas excepciones-, que da base a una definición generalizadora ${ }^{1}$.

¿Podría decirse que la esencia o el factor definidor de esta situación disyuntiva son las armas y/o el oficio de las arcas? Sin ningún género de dudas. Se puede comprobar a través de una visión general de los estamentos que conforman la sociedad medieval y de su evolución a lo largo de toda la Baja Edad Media.

Tomando como punto de partida el estudio que de la población de la Extremadura leonesa de los siglos XII y xIII hace M. T. Gacto ${ }^{2}$, se llega a la conclusión de que en este período de repoblación y expansión de los concejos los caballeros villanos, que además de erigirse en el grupo de mayor prestigio se van a reservar prácticamente en exclusiva las magistraturas del concejo, se caracterizan por la posesión de caballo-armas. Veamos lo que dice al respecto: «En principio, debido a las necesidades de este tipo de guerrero, se exige el caballo-armas de forma indeterminada. Posteriormente se tenderá a buscar una mayor eficacia en el caballero,

' La singularidad de la condición de exento dentro de la sociedad venía dada por la aspiración de todo pechero a lograr la exención. Ello equivalía a escalar un puesto en la pirámide social. S. DE Moxo, Exenciones tributarias en Castilla a fines de la Edad Media, en «Hispania», XXI (1961), pág. 165: «Como quiera que la tributación era una base efectiva de discriminación entre el hidalgo y el pechero, los beneficiarios de este privilegio se acercaban de este modo a la hidalguía.»

M. T. GaCto Fernández, Estructura de la población en la Extremadura leonesa en los siglos XII y XIII, Centro de Estudios Salmantinos, Salamanca, 1977. 
para lo cual se determina el valor que ha de tener el caballo y los distintos tipos de arma que deben acompañarlo, otorgando en relación a ello diferentes privilegios. [...] La posesión de caballo y armas es la que da la condición de caballero y, por tanto, sólo será transmisible a los que hereden estos elementos. Los fueros protegen estas propiedades del caballero, al reservarlas para él, excluyéndolas del reparto de los bienes matrimoniales a la muerte de la mujer» ${ }^{3}$.

No constituye tampoco ninguna novedad, es un ejemplo preciso de algo que de forma general ya habían puesto de manifiesto C. Pescador ${ }^{4}$ y A. Bo y M. C. Carlé ${ }^{5}$.

Siguiendo a Gacto, veamos cuáles eran las obligaciones de estos cabaIleros: «Los servicios más característicos del caballero eran, por supuesto, los servicios de guerra. [...] Fuera del servicio militar encontramos al caballero acudiendo a juntas o medianedos. No recibía ningún sueldo fijo por todos estos servicios, pero a cambio de ellos se le recompensaba con una serie de privilegios y ciertas cantidades que pueden ser consideradas como su retribución. [...] El servicio de guerra proporcionaba también una participación en el botín» " .

La conclusión a que quería llegar es que «disfrutan además de otros privilegios indirectos que tomarían también con carácter de retribución: se les libera de los pechos debidos en principio como vecinos que eran» ${ }^{\top}$.

Si respecto al estamento de los bellatores queda clara su relación armas-exención, veamos qué dice al respecto sobre los oratores el estudio de M. T. Gacto según los fueros de la Extremadura leonesa.

Divide en su estudio el estamento clerical en clero regular y secular. Respecto a aquél, en el que incluye también a las órdenes militares, dice: «Los monasterios, titulares de territorios que el rey les encomendaba para su repoblación y defensa como premio a su colaboración en la guerra, permanecían al margen de estos concejos aun estando enclavados muchos

'Ibúd., págs. 114-115. En al Fuero de Ledesma se establece, según normas legisladais por Fernando II. el número de excusados que cada caballero puede tener en relación con las armas que posee.

- C. Pescnior, La caballeria popular en León y Castilla, en CHE, XXXIIIXXXIV, XXXV-XXXVI, XXXVII-XXXVIII, XXXIX-XL.

A. Bo y M. C. Carlé, Cuándo empieza a reservarse a los caballeros el gobierno de las cindades castellanas, en CHE, IV (1946).

"Ibid., págs. 116-117.

'Ibid, págs. 118-120: «En el aspecto fiscal, siguiendo con el estatuto del caballero, lo vimos en ventajosa posición respecto a los restantes vecinos: en Salamanca, libres de pecho, y en Ledesma, también de pedidos; esta situación privilegiada la hacemos extensiva a los restantes fueros que estudiamos... Los caballeros estaban exentos sólo parcialmente de las cargas del concejo: estaban obligados a cumplir los servicios militares de forma más costosa que los peones, lo que justificaba la excusación de algunos impuestos.... 
de ellos en el interior de sus términos. [...] Este hecho... puede llevar a pensar que los fueros tomaban medidas ante un hecho tal vez frecuente: el que algunos vecinos se evadieran de las cargas fiscales y servicios debidos al concejo, vinculándose a estas órdenes y en consecuencia haciendo más gravosos los impuestos sobre la población pechera» ${ }^{8}$.

En relación al clero secular, Gacto admite que paralelamente al avance de la Reconquista van creándose nuevas sedes episcopales o reorganizándose las antiguas ${ }^{9}$.

Este estamento, que establece entre sí diversas jerarquías, goza, sin embargo, de ventajas y privilegios en razón de su escala: «El obispo, canónigos y dignidades del Cabildo mencionadas en el Fuero de Salamanca constituirían un sector de privilegiados prácticamente indiferenciados en el ámbito local. Las posesiones del obispo y del Cabildo eran numerosas y proporcionaban considerables ingresos. Importantes eran también los derechos económicos que tenían sobre la misma población concejil.» Pero también el clérigo: «La vida del simple clérigo se desarrollaba en torno a la parroquia. En cada una de ellas podían servir dos clérigos y todos se asociaban, bajo la dirección de un abad elegido entre ellos, en el Cabildo de Clerecía. [....] En el año 1259 puede considerarse desarrollada la regulación de los derechos de la clerecía. [...] En 1202, como recompensa a los servicios prestados en la Reconquista-repoblación, Alfonso IX le concede el señorío y la jurisdicción sobre el Corral de San Mar$\cos \ldots\rangle^{10}$.

«En el orden fiscal, el clérigo se encuentra "franquido e escusado e libre de fonssado, de pecho, de atalaya, de lavor de castiello, de toda pecha e de toda fazendera..." " ".

La conclusión es que también este estamento, además de poseer y/o controlar importantes riquezas, gozil de privilegios de exención que no proceden exclusivamente de su función religiosa, sino que, como cn dos o tres ocasiones se manifiesta, tiene algo que ver con el hecho de la Reconquista, y en concreto en lo que respecta a las órdenes militares deja fucra de toda cluda, de lo que se puede afirmar que si en el estamento de la caballería la exención fiscal viene dada por el oficio de las armas, en el estamento religioso no está tampoco muy lejos la razón de este privilegio en las armas, al menos en un principio y para la mayor parte del clero, puesto que en lo relativo a las órdenes militares por su propia función es claro.

" Ibid., páns. 158 y 160.

"lbid. pág. 161.

"Ibíd., pígs. 164-165.

"Lbíd., pág. 167. 
¿Qué ocurre con el pueblo llano, el estamento de los laboratores? Lal consideración general de todos los vecinos que moran en los nuevos concejos según establecen los Fueros es la de ser libres: "La libertad del vecino regulada en estos fueros está relacionada con la condición de ser pechero. Podemos decir que, en principio, todo vecino es pechero: está sometido a las cargas y servicios fiscales del concejo y, a través de éste, del rey. En este elemento, la pecha, se encuentra el fundamento de la protección que los fueros ofrecen al vecino y es lo que justifica el disfrute de los biencs del concejo. [...] Sobre esta norma general hay que señalar numerosas variantes que se derivan de las exigencias surgidas a lo largo de la vida del concejo. Bien para favorecer el desarrollo de algunas actividades necesarias al concejo (como son las militares, o... caso de algunos menestrales), bien para proteger a grupos más desafortunados o como recompensa al servicio prestado en los puestos del concejo, los fueros excusan de mancra parcial o total a algunos vecinos» ${ }^{12}$.

Los clérigos, que no figuran como vecinos, y los vecinos pecheros, por su escasa influencia, quedarán marginados de los oficios públicos, que selán ocupados y monopolizados por los caballeros ${ }^{13}$.

Esta situación se acentúa y se agudiza a lo largo de la Baja Edad Media, sobre todo cuando al estamento clerical, único capaz de aspirar a ocupar oficios concejiles, se le prohíbe durante el reinado de Juan II acceder a los mismos ${ }^{14}$.

Estal situación se puede extrapolar y gencralizar para otras áreas del reino de Castilla; a modo de ejemplo, Gautier Dalché ha observado un caso similar en Sepúlveda, donde se da la división del concejo en dos grupos antagónicos: los pecheros, representados en el concejo por un grupo reducido de hombres buenos, y los no pecheros, caballeros que se reservan el gobierno del concejo ${ }^{15}$.

Esta división que de forma monográfica mencionó Sepúlveda es la evolución normal de la vida interna de todos los concejos, y ejemplifica una situación que dimana de la profesión o ejercicio de las armas y que llcva aparejada la exención u obligación de pagar impuestos, según el grupo social al que se pertenezca.

12 Ibid., págs. 49-50.

"Es la conclisión a que llega M. T. Gacto. Un trabajo de mayor amplitud ya ha sido mencionadio: $\Lambda$. Bo y M. C. Cinst.́, Cuóndo empieza..

14 Archivo Municipal de Ciudad Rodrigo (A.M. C. R.), leg. 287, doc. 30, año 1430. Las Cortes de Toledo de 1480 lo sancionan de nuevo. Libro de Cortes, II, págs. 53 y sigs.

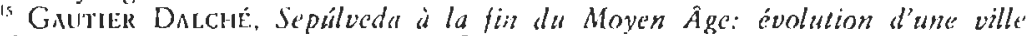
castillan" "le la Meseta, en "Le Moven Āge», LXIX (1963), págs. 805 y sigs. 
Más explícito es el ejemplo que Teófilo $F$. Ruiz of rece de la ciudad de Burgos ${ }^{16}$.

Auncue la realidad histórica y social es más compleja, y no he mencionado la población rural, considero que en líneas generales la exposición es válida y en ella no interfiere en nada la ausencia de la alusión al campo por su carácter casi exclusivamente agrario y pechero.

Es el oficio y el prestigio de las armas, que conlleva una idiosincrasia particular gestada en el hecho militar de la Reconquista, lo que cxime a este grupo de los pechos y lo que le lleva al dominio de los concejos; por cllo la profesión de las armas justifica gran número de actitudes y procederes. Es el caso significativo de don Juan Manuel en el Libro de los Eslados: "Todos los estamentos del mundo... se encierran en tres: al uno llaman defonsores, et al otro oradores, et al otro labradores» ${ }^{17}$, concepción ideológica concebida para justificar una situación de privilegio desde la perspectiva de los privilegiados y como testimonio contemporáneo, que resulta, por demás, muy ilustrativo. Tanto más cuanto que si dejamos a un lado la alta nobleza, para la que resulta obvia cualquier afirmación en este sentido, nos encontramos con que en los niveles más bajos de la caballería, y sin pertenecer a la nobleza de sangre, ya desde el siglo $\mathrm{x}$ en Castilla, y en lo sucesivo, se gesta una caballería villana, a la que he venido haciendo alusión en páginas precedentes, que terminaron identificándose con la pequeña nobleza. En su origen eran labradores o ganaderos, pequeños propietarios que podían costearse un caballo para participar en la guerra, en la que desempeñaron un importante papel, obteniendo diversos privilegios de los monarcas.

Mucho más importante que este proceso, que cristalizó de una minelal lógica, para tratar de ilustrar este trabajo, es el cambio cjue desde el siglo xul se observa en lo que respecta al acceso a la caballería ${ }^{18}$ : está obligado a mantener caballo y armas todo el que posee un determinado patrimonio; por esta condición recibieron el nombre de caballeros de cuantía.

De este modo, el oficio de la guerra que justifica el prestigio y la exención de un grupo social, cambiará su signo y permitirá que a través

In TFíflio F. Ruiz, Sociclad y poder real en Castilla, págs. 154-155: «Al igual que en el resto de Castilla, los ciudadanos de Burgos se habían visto obligados a servir militarmente en el siglo $\mathrm{x}$ y siguieron sirviendo al reino durante los siglos $\mathrm{xin}$ y xiv. [...] El 22 de febrero de 1255, Alfonso X concedía exención de tributos a aqueilos ciudadanos de Burgos que poscían caballos y armas...»

${ }^{17}$ Iuan Manuli. Libro de los Estados, ed. de T. M. Castro, Universidad de Barcelona, 1968.

1* J. Valdó́n BARuque, Feudalismo y consolidación de los pućblos bispónicos (sighos XI-XV) (Dedicado a Castilla), Ed. Labor, Barcelona, 1980, pág. 51. 
de la riquezat se pase a prestar el servicio de las armas que libera de la tributación monetaria al que lo logra.

$\mathrm{Ni}$ que decir tiene que si este privilegio se concede a los allegados, se ha de dar por supuesio a aquellos que en sus distintas escalas componen la orden de caballería.

Estos caballeros de cuantía constituían en general el grupo dominante en las ciudades ${ }^{19}$. Se denominan también caballeros de alarde, y quizá este término sea más ilustrativo, o al menos más sugestivo, de lo que representaba la dicotomía armas-impuestos, entendiendo éstas como prestación monetaria y aquéllas como impuesto-servicio, y ello porque no es ninguna novedad afirmar que la carga fiscal que sufre la población pechera medieval es brutal y agobiante y que la mayor aspiración de todo pechero era escapar a su sino, logrando la exención a través del servicio que se prestaba con armas y que por basarse en la fortuna tenían que demostrar anualmente. Ello deja ver con claridad el esfuerzo que determinadas personas debían hacer para lograrlo, para mantenerse y no perder la exención; pero podría también dar lugar a picaresca, haciendo alarde y vendiendo después el caballo o las armas, tomándolos prestados, etc., que naturalmente es atajada por los jueces, que son las justicias y autoridades concejiles ${ }^{20}$.

En este esquema falta algo. Podría pensarse que cómo se explicaría la situación del clero a través del concepto fiscal armas-impuestos.

Bien, aunque ras la justificación divina de la división de la sociedad en tres estamentos la función reservada al clero es la guía espiritual, no puede dejarse a un lado que paralelamente a la Reconquista y repoblación una parte de este estamento tuvo relación con las armas y la guerra, y sin que con ello quielas generalizar una actitud, aceptando que el estamento réligioso tiene un caráctel y una defínición propia por la cual se distingue, diferencia y en ocasiones contrapone al sector laico, por lo que resulta difícil -en este y en otros temas- englobat en una misma explicación conceptos que son heterogéneos; no hay que olvidar el papel relevante que las órdenes miltares - y los maesırazgos como cargos políticos, por ejemplo- ostentan en los siglos finales de la Edad Media y que el mismo estamento clerical se nutre en una parte importante de sus altas jerarquías con clementos segundones procedentes de familias del orden ecuestre.

11) J. Var.prón, op. cit., pág. 132.

2* A. Bernal Estévez, Ciudud Rodrigo en la Edad Media, Salamanca, 1981, pígina 161 , apéndice documental. 


\section{Aplicación al caso de Ciudad Rodrigo}

T'ras este planteamiento general, que naturalmente no es nuevo, veamos cuál es el comportamiento de la población de Ciudad Rodrigo en relación al mismo y a través de algunos documentos o noticias que puedan ilustrarlo.

Y voy a partir de la consideración del uso o posesión de las armas como concepto fiscal definidor de una situación y diferenciador de dos posiciones distintas ante la Hacienda: los que gozando del estatuto de caballero se eximen del gravamen pecuniario y los que no gozando de él tienen que pechar.

La bisagra entre estos dos mundos está representada por la caballería cuantiosa o de alarde. Entremos en su mundo.

Su capacidad económica, que les permite mantener un caballo y armas $y$, por tanto, en aptitud de prestar un servicio militar ecuestre, les exime de pechos, pero a cambio de la obligación de hacer periódicamente alarde público de su condición de caballeros, privilegio que pierden cuando le faltan estos requisitos. Más que una obligación de mantener caballo y armas por su capacidad económica, como antes afirmaba, siguiendo a Valdeón, además habría que considerarlo como una aspiración del común para acceder a través de las mismas al escalón de la exención.

Veamos la casuística al respecto de los alardes que tienen lugar el día de San Martín en el arrabal de San Francisco de la ciudad, frente a la iglesia de San Andrés, el año 1458, y ante el lugarteniente de alcalde Ihoán de Caranco, algunos regidores, un notario y el sexmero de la ciudad ${ }^{2 !}$.

Sc realizan diecisiete alardes de otras tantas personas, de las que catorce son vecinos de la ciudad y las otras tres del alfoz, uno del lugar de Zamarra y las otras dos de Sancti Spiritus, y que deben presentar una casa de asiento en la ciudad donde poder requerirles como caballeros para ser admitidos y considerados como tales ${ }^{22}$.

Casi todos cumplen con los requisitos precisos, es decir, su presencia f́sica, la de su caballo y las armas que poseen. Pero algunos casos presentan ciertas particularidades:

Ausencia del caballero. Martina Ramos, mujer de Pedro, carnicero, se presenta en lugar de su esposo, que se encuentra ausente ese día, con el caballo, hace alarde de las armas; Pedro, hijo de Ferrand Gutiérrez, carnicero, hace alarde con el caballo y las armas de su padre, que estaba fuera de la ciudad.

21 A.M.C. R., Acuerdos municipales 1458-1460, sin signarura, año 1458, doc. 79.

22 Ibid., doc. 120. 
Ausencia del caballo. Francisco Cristóbal presenta sus armas, pero declara no tencr caballo, aunque comprometiéndose a comprarlo en el plazo fijado; Fernando, carnicero, hace la presentación de sus armas y manifiesta que termina de vender el caballo, pero que en el tiempo indicado comprará otro; Juan Prieto, vecino de Sancti Spiritus, muestra sus armas, pero no el caballo, sobre el que declara haberlo enviado a la guerra de Granada.

En todos los casos se les recibe como caballeros de alarde, con el compromiso de presentar el caballo. En ninguna ocasión faltan las armas al alarde.

¿Qué armas? No todos los caballeros presentan el mismo número y las mismas armas: la ceraza se repite en todos los casos, catorce veces presentan lanza, trece espada y diez daga, en cuatro ocasiones armadura de cabeza y en dos casquete. En un caso les basta con presentar coraza y armadura de cabeza, aunque lo habitual es portar coraza, lanza y/o espada y daga, o bien coraza con lanza, espada y casquete o armadura de cabeza.

¿Quiénes eran estos caballeros de alarde? Gente del común dedicados a actividades artesanales en su mayoría; de los casos en que la documentación ofrece información de su profesión se extrae la siguiente relación: cuatro carniceros, dos armeros, un zapatero, un zahonero y un hortelano; en otro caso, aunque no cita profesión, sí origen: hijo de un clérigo.

La actuación del concejo ante estos caballeros es la de su protocolaria aceptación; sin embargo, resulta interesante y muy propio aquí mencionar la reacción del sexmero del campo del Yeltes, representante del común y, por tanto, de los pecheros de este sexmo, ante el alarde de Juan Prieto, vecino de Sancti Spiritus, al que se opone alegando perjuicio para los pecheros que él representa, porque así tendrían que pagar más. En cste caso, es claro que el aspirante a caballero hace alarde por primera vez y recibe, no obstante, la confirmación concejil, con lo que logra evadirse de las cargas que soportan sus convecinos.

Es preciso matizar que no sólo las armas son el vehículo de la exención, privilegios reales, cartas de vecindad, etc.; son otros caminos yue, sin embargo, hay que aclarar, ya que ni comportan un prestigio social, ni gozan de protección legal, ni responden a un ordenamiento generalizado y válido para toda la población ${ }^{23}$.

$\mathrm{Si}$ antes me refería a una idiosincrasia caballeresca que es fruto de una

2: Naturalmentc, establecer la ecuivalencia armas = excnción, no armas = pechero, no es ni pucde ser admitido pol válido. La exención de impuestos o de ciertos impuestos se obtiene por diversas vias (en mi tesis doctoral se estudia amplianente este tema). pero es sobre todo lo que significa y comporta perteneccr al orden de caballeria. 
historia y una tradición guerreras como consecuencia del enfrentamiento secular entre musulmanes y cristianos en la España medieval y que tuvo una particular importancia en el reino de Castilla ${ }^{24}$, yo quiero profundizar en el hecho definidor de las armas y su inserción en la mentalidad de la época, hasta el punto de que además de la consideración de las armas como concepto fiscal, éstas introducen un principio de diferenciación en la cstructura social de manera que a cada catcgoría, grupo o jerarcyuía social corresponde el uso de determinadas armas por no hacer la formulación a la inversa, hipótesis que requeriría un estudio más detallado y exhaustivo y determinados hábitos y modos de vida concretos ${ }^{25}$. La pertenencia a un grupo sucial exige el empleo de unas armas específicas; así, la ballesta es arma de infantería reservada a la población pechera, la coraza o el casquete de la caballería popular y la loriga o armadura de la nobleza; también, y de forma más simplificada, los pecheros constiúuían la infantería y el peonaje de los ejércitos, mientras los privilegiados la caballería.

Si existe una correspondencia en el uso de determinadas armas según el grupo social al quic se pertenece y ésta no es muy nítida en los niveles de la cuballería, sí cuue lo es, en cambio, en el mundo de la pechería porque su organización y estrucluración por motivos fiscales es más concisa.

La documentación bajomedieval de Ciudad Rodrigo distingue dentro de la población pechera tres niveles distintos según su grado de aportación fiscal basalda en la fortuna, que son los pecheros de pecha completa, los pecheros de media pecha y los «de más baxa manera e menor fazienda" ${ }^{2 *}$. que están exentos de pechar y que se corresponden con una fortuna personal en biencs muebles y raíces superior a 10.000 maravedís, entre +.000 y 10.000 , y los que no llegaban a 4.000 , respectivamente. Con base a esta división, cl concejo establece y obliga en 1459 a esta poblatción a tener determinadas armas, que son las siguienies: los pecheros de pecha completa, que son los de mayor nivel de forruna, una ballesta de acero con doce pasadores y una espacla; los pecheros de media pecha, cadar uno un escudo y una espada, y los exentos por pobres, una lanza y un durdo o azagaya ${ }^{2 i}$. Lil justificación está basada en la defensa de la ciudad y los términos de su tierra y motivó la creación de una renta para

"I. VAIJEÓN, op. cil., príg. 51.

" M. A. Ladero, lispuña e'n 1492, Ed. Hernando, Madrid, 1978. Entre la enumeración de todos los privilegios, preeminencias y cxenciones del estamento aristocrático, señala: "Había, por último, una scric de signos sociales y hábitos externos peculiares de la manera noble de vivir: la espada y las amas, las pautas de cunducta de tipo caballertesco, etc.» (pág, 43).

A. M. C. R., Acurerdos inunicipales 1459, docs. 58 y 69.

Ibid, leg. 286, libro viejo de ordenanzas, fol. 186 v. 
obligar a los labradores a la adquisición de estas armas a los que se habían mostrado reticentes y a los que requieren para que no las vendan, empenen ni den. Por su parte, el concejo les protege dichas armas de cualquier empeño por deudas y/o gravámenes reales o concejiles.

Esta correspondencia entrc pecheros y armas está también reflejada implícitamente en otro documento del año $1459^{28}$.

2* A. M.C.R., Acuerdos municipales I, año 1459, doc. 21: traslado de la carta de las catorce monedas y pedido (12 de abril de 1459); lo que debe pagar cada pechero «y que le sea guardaclo a cada uno la cama cn que durmiere, las ropas que vestiere continuamente, e las barmas que loviere, las que de razón devicre tenér, segund la persona que fuer... e asý mismo, un par de bueyes de labrança» (subrayado del autor). 